\title{
Sexual Satisfaction in Patients with Diabetes Type 2 and Their Partners
}

\section{Graça Pereira ${ }^{1 *}$, Olinda Marques ${ }^{2}$, Ângela Rodrigues ${ }^{1}$, Jónia Santos ${ }^{1}$ and Susana Pedras $^{1}$}

${ }^{1}$ University of Minho, School of Psychology, Portugal

${ }^{2}$ Hospital of Braga, Endocrinology Service, Portugal

\section{Abstract}

Aim: Sexual health is a very important topic in diabetes. This paper examines the impact of diabetes on the sexual relationship of patients with diabetes and their partners.

Methods: A sample of 87 patients with type 2 diabetes and their partners participated in the study. Instruments used were: Revised Dyadic Adjustment Scale (RDAS), Sexual Dysfunctional Beliefs Questionnaire (SDBQ), Sexual Beliefs and Information Questionnaire (SBIQ), Index of Sexual Satisfaction (ISS) and Diabetes Adherence (DA).

Results: Results showed that there were differences in psychological variables according to gender, age, education and illness duration. Adherence was positively correlated with sexual information and negatively with dysfunctional beliefs, in patients. Sexual satisfaction, in patients, was positively correlated with dyadic adjustment and negatively with dysfunctional sexual beliefs. Patient's sexual satisfaction was also positively related with partner's sexual information, dyadic adjustment, sexual satisfaction and negatively with dysfunctional beliefs. In both patients and partners, female gender, more sexual dysfunctional beliefs and less dyadic adjustment were predictors of sexual dissatisfaction.

Conclusion: This study highlights the intrinsic relationship between sexual beliefs, dyadic adjustment and adherence, in patients with diabetes type 2 and their partners emphasizing the need to use a dyadic approach in this population.

\section{Introduction}

In Portugal, $13 \%$ of the population suffer from Type 2 diabetes [1] Diabetes is known to cause multiple medical, psychological and sexual problems in both men and women [2,3]. According to Schover [4] and Wandell and Brorsson [5], dyadic relationships may suffer changes after a diagnosis of a chronic disease and, as a result, sexual difficulties may arise in the couple. In fact, marital support is an important aspect when the couple has to deal with a chronic disease [6,7]. The influence of dyadic adjustment is greater when one of the elements has to deal with the complexity of the diabetes regimen (e.g. buying and preparing food, medication administration, getting involved in physical exercise) [6]. Literature shows that couples presenting less marital satisfaction [8-11], report less communication and problem resolution skills $[12,13]$ and more difficulty in handling tasks related to diabetes. Patients' self-care behaviors decrease when there is conflict in the relationship and criticism has been associated with a poor glycemic control [14]. However, several studies have shown that patients with diabetes report a good marital adjustment, higher satisfaction with disease management (treatment, appearance, activity), a lesser impact of diabetes on their lives as well as less emotional stress related to diabetes [8-11,15]. In fact, Trief and collaborators [8] reported that better dyadic adjustment was associated with a better adaptation to diabetes, less emotional distress, and better quality of life. The authors also found that the marital relationship was a better predictor of glycemic control than family support. A supportive partner was associated with the patient's quality of life, adjustment to the illness [16], and adherence to self-care behaviors [17].

Sexual problems may be a consequence of diabetes and may lead to a lack of adherence to treatment and problems in intimate relationships [18]. Sexual problems that are not recognized may impair quality of life [18] and the quality of the intimate relationship. In fact, several studies reveal that better dyadic adjustment has been associated with better sexual functioning [19-23] and marital satisfaction had a positive impact on sexual satisfaction [23]. Women with diabetes, with high prevalence of sexual dysfunction also showed lower satisfaction with the marital relation, lower quality of life and more depressive symptoms [24-26]. Recently, Pedersen et al. [27] found that sexual desire and low satisfaction are often reported among men and women with diabetes. Therefore, sexual satisfaction needs to be taken in consideration given its fundamental role on sexual health and wellbeing [28].

According to the literature, sexual dysfunctional beliefs are associated with less sexual satisfaction [29]. Sexual education decreases be-liefs in sexual myths [30] since many beliefs held about sexual attitudes and behaviors are based on stereotyped views of sexuality. Not having accurate sexual information has been related to less sexual satisfaction. In a study that addressed beliefs regarding what is "adequate", " desirable" and "too short" or "too long" intravaginal ejaculatory latency time among those with sexual dysfunction, dysfunctional beliefs were correlated with impotence, premature ejaculation and dissatisfaction. Therefore, sexual beliefs may affect the patient's quality of life and lead to distress and displeasure. Since stereotype is the main determinant of expectation, dissatisfaction due to wrong perception, may impact significantly the individual's self-esteem and quality of life causing emotional distress and leading to relationship problems [31]. Sexual health in diabetes is a very important topic and has been defined as the integration of somatic, emotional, intellectual and social aspects in ways that are positively enriching [32] with an impact on how the individual perceives and manages one's sexuality, setting a norm against which people identify "sexual problems". However, few patients openly discuss sexual problems with their family physician [18]. At our knowledge, there are only one study about the role of sexual dysfunctional beliefs and

"Corresponding Author: Prof. M. Graça Pereira, University of Minho, School of Psychology, Campus de Gualtar, 4710-057, Braga, Portugal, Fax: +351 253678 987; E-mail: gracep@psi.uminho.pt

Citation: Pereira MG, Marques O, Rodrigues A, Santos J, Pedras S (2016) Sexual Satisfaction in Patients with Diabetes Type 2 and Their Partners. Int J Psychol Behav Anal 2: 117. doi: https://doi.org/10.15344/2455-3867/2016/117

Copyright: () 2016 Pereira. This is an open-access article distributed under the terms of the Creative Commons Attribution License, which permits unrestricted use, distribution, and reproduction in any medium, provided the original author and source are credited. 
sexual satisfaction in women and men with diabetes, that showed that women with diabetic husbands showed a higher mean score in sexual dysfunctional beliefs than women with non diabetic husbands [33]

One of the consequences of diabetes includes sexual dysfunctions and sexual dissatisfaction. Sexual disorders among men with diabetes may affect quality of life significantly because there is a high likelihood of developing vascular and neurological complications that result from hyperglycemia as well as psychological problems [34] or a combined effect of some of these factors [35-37]. As a result, some patients are reluctant to take their medication lowering their adherence to the diabetic regimen. Adherence to self-care behaviors is an important issue for clinicians. Non-adherence is considered a public health problem [38]. The low rate of adherence may adversely affect disease progression and consequently, quality of life [39] resulting in an increase in mortality, number of consultations, hospitalization and/or unnecessary costs to the health care system $[40,41]$. Non-adherence to medication is a major issue in diabetes since adherence is essential in the prevention of diabetes complications [42].

According to a recent systematic review about sexual satisfaction [28], there are many factors that contribute to sexual satisfaction, such as: individual factors (socio-demographic and psychological variables), factors related to intimate relationships and sexual response; factors re-lated to social support and family relationships and finally, factors related to cultural beliefs and values. In this study, the focus was in individual factors (sociodemographic and clinical variables as well as sexual dysfunctional beliefs and sexual information) and intimate relationships (dyadic adjustment), in order to explore their contribution to sexual satisfaction, in patients and partners.

In Portugal, very few studies have addressed the impact of the predictors of sexual satisfaction in patients with diabetes and their partners. Therefore, this study focused on: 1) differences on psychological variables according to gender, education level, age and duration of illness; 2) the relationships among dyadic adjustment, sexual information, dysfunctional sexual beliefs, adherence and sexual satisfaction; 3 ) predictors of sexual satisfaction in patients and partners.

\section{Methods}

\section{Sample}

Participants were 87 patients with type 2 diabetes and their partners $(\mathrm{n}=174)$. Average age was 62 years old for male patients (SD: 12.52) and 59 years old for female patients (SD: 14.1). In this sample, $49 \%$ of patients completed elementary school, $18.3 \%$ finished high school and $8.7 \%$ has a university degree. Diabetes duration was 12 years on average (SD: 9) for male patients and 9 years (SD: 7.0) for female patients. Regarding the marital status, $93 \%$ of patients were married. $47 \%$ of male patients and $77 \%$ of female patients showed diagnosed diabetes complications such as retinopathy and nephropathy. Only $6 \%$ of males and $3 \%$ of females reported having difficulty with sexual performance. Age average for male partners was 50.65 years old $(\mathrm{SD}=2.45)$ and 61.67 years old for female partners $(\mathrm{SD}=2.09)$. In terms of education, $4.8 \%$ of partners finished ele-mentary school, $20.3 \%$ high school and $6.3 \%$ a university degree.

Patient's recruitment was conducted in two institutions in the North of Portugal: an Association of Patients with Diabetes and a Central Hospital where patients received their routine diabetes care. The procedures involved a first telephone contact introducing the study and inviting patients to participate with their partner.
When the patient agreed to participate, an appointment before or after the next routine consultation was set. The couple signed a written consent before answering the questionnaires. Exclusion criteria for participation were: 1) having a psychiatric disorder and 2) having other chronic disorder or medical condition affecting sexual functioning (e.g. paraplegias). Patients from the Association were no different than those from the hospital, in clinical and socialdemographic characteristics.

\section{Instruments}

In order to study individual and couple's variables in patients with diabetes and their partners, the following instruments were used:

- Dyadic Adjustment was assessed by the Revised Dyadic Adjustment Scale (RDAS) [43,44] a 14-item questionnaire composed of three subscales: cohesion, satisfaction and consensus. Items are presented in a 5-point-scale. A higher score indicates better adjustment. In this study, only the total scale was used. Reliability in this sample was .76.

- Dysfunctional Beliefs were assessed with the Sexual Dysfunctional Beliefs Questionnaire (SDBQ) [45]. This questionnaire has a femi-nine and a masculine version. It is composed of 60 items that assess specific sexual beliefs, considered relevant in the development of sexual dysfunctions, in 6 subscales: beliefs regarding sexual conservatism, sexual desire as sin, aging, body image, affection and maternity. The male version has the following domains: sexual conservatism, female sexual power, 'macho' beliefs", beliefs about women's sexual satisfaction and restricted attitude toward sexual activity. Items are presented in a 5-point-scale. In this study, only the total scale was used. A higher score indicates more dysfunctional beliefs. Reliability in this sample was .91 .

- Sexual Beliefs and Information were assessed with the Sexual Beliefs and Information Questionnaire (SBIQ) [46, 47], a 20 -item questionnaire that assesses information and sexual knowledge in 5 subscales: availability, stress/pressure, aging, sexual satisfaction and basic information. In this study, only the total scale was used. Items are presented in a 5-pointscale. A higher score indicates more correct sexual beliefs and information. Reliability in this sample was .70.

- Sexual satisfaction was assessed with the Index of Sexual Satisfaction (ISS) [47, 48], a 25 item questionnaire that assessed degree, severity or magnitude of a problem with the sexual component of a couple's relationship. Items are presented in a 5-point-scale. A higher score indicates more sexual problems. Reliability in this sample was .90 .

- Adherence was assessed with the Diabetes Adherence [49], a 5-item questionnaire that assesses adherence to self-care behaviors, in patients, regarding diet, physical exercise and medication. Items are presented in a 5-point-scale. A high score indicates lower adherence. Reliability in this sample was .75 .

\section{Data analysis}

In order to examine differences according to gender a $t$ test was performed as well as chi square tests regarding education, age and illness dura-tion, on all psychological variables. A Pearson correlation was done to analyze the relationships among patients and partners variables. To test the differences between patients, according to 
Citation: Pereira MG, Marques O, Rodrigues A, Santos J, Pedras S (2016) Sexual Satisfaction in Patients with Diabetes Type 2 and Their Partners. Int J Psychol Behav Anal 2: 117. doi: https://doi.org/10.15344/2455-3867/2016/117

Page 3 of 6

gender, education level, age and illness duration, a Kruskal-Wallis test was performed. Predictors of sexual satisfaction were tested using a multiple regression analysis (method enter) for patients and partners. In the first block, gender and illness duration were introduced and in the second block, the psychological variables (dyadic adjustment, sexual dysfunctional beliefs, and sexual beliefs, and information).

\section{Results}

Differences on patient's Psychological Variables according to Gender, Education Level, Age and Illness Duration

Differences were found on dyadic adjustment, sexual satisfaction and sexual dysfunctional beliefs. Female patients presented more marital adjustment $(\mathrm{t}=2.23, \mathrm{p} \leq .05)$ and sexual dysfunctional beliefs $(\mathrm{t}=4.86, \mathrm{p} \leq .001)$ than male patients. On the other hand, male patients showed more sexual satisfaction than females $(\mathrm{t}=2.66, \mathrm{p} \leq .05)$.

Patients with elementary school education had more dysfunctional beliefs than those with a college education $\left(\chi^{2}=19.5, \mathrm{p} \leq .000\right)$ and the latter had more correct sexual information $\left(\chi^{2}=8.90, \mathrm{p} \leq .012\right)$ Younger patients ( $<$ below 65 years old) showed more adherence $\left(\chi^{2}=22.3, p \leq .000\right)$ and the oldest group ( $\geq 65$ years old $)$ presented more dysfunctional beliefs $\left(\chi^{2}=63.8, \mathrm{p} \leq .000\right)$ when compared with the younger and the middle age groups (between 51 and 64 years old). Older women reported better sexual functioning than younger women $\left(\chi^{2}=8.07, \mathrm{p} \leq .018\right)$. Regarding illness duration, patients with diabetes less than 10 years presented more dysfunctional beliefs than those between 10 and 24 years or longer than 25 years $\left(\chi^{2}=6.76, p \leq\right.$ $.034)$.

Relationships between Dyadic Adjustment, Sexual Information, Dysfunctional Sexual Beliefs, Sexual Satisfaction and Patients' Adherence

The results revealed that adherence was positively related with sexual information $(\mathrm{r}=.254, \mathrm{p} \leq .05)$ and negatively with dysfunctional beliefs $(r=-.310, \mathrm{p} \leq .00)$, in patients. No partner's variables correlated with patient's adherence.

Relationships between Dyadic Adjustment, Sexual Information, Dysfunctional Sexual Beliefs and Patient's Sexual Satisfaction

Sexual satisfaction was positively related to dyadic adjustment $(\mathrm{r}=5.30, \mathrm{p} \leq .001)$ and negatively with dysfunctional sexual beliefs, in patients ( $\mathrm{r}=-.215 ; \mathrm{p} \leq .05$.) Patient's sexual satisfaction was also positively related with partner's sexual information $(r=.269 ; \mathrm{p} \leq .05)$, dyadicad

\section{Predictors of Sexual Satisfaction in Patients and partners}

In patients, the model of the regression analysis showed that gender and sexual dysfunctional beliefs were positive predictors of sexual dissatisfaction and dyadic adjustment was a negative predictor, in patients, explaining $38 \%$ of the variance.

In partners, the model of the regression analysis showed that gender and sexual dysfunctional beliefs were positive predictors of sexual dissatisfaction and dyadic adjustment was a negative predictor, in partners, explaining $22 \%$ of the variance (Table 1 )

\section{Discussion}

One goal of this study was to find differences according to gender, education, age and illness duration, on all psychological variables. Results showed that female patients presented higher marital adjustment and sexual dysfunctional beliefs than male patients. Nobre and PintoGouveia [50] found females to have more dysfunctional beliefs than males particularly regarding age and body image. Also, according to Adams and collaborators [46], more incorrect sexual information was associated with sexual dysfunctional beliefs. In fact, sexual dysfunctional beliefs are considered a moderate risk factor for sexual problems [50]. On the other hand, male patients showed more sexual satisfaction than females. Verbrugge [51] and Kandrack, Grant and Segall [52] found similar results and less burden in males regarding diabetes when compared with females [53].

Patients with elementary school education had more dysfunctional beliefs than those with college and the latter had more correct sexual information. In fact, more education may provide access to better and more resources as well as information regarding diabetes [54, 55].

Younger patients showed more adherence. This result is intuitive since younger patients may be more concerned with the possible complications of diabetes and their impact on sexual performance. Older patients reported more dysfunctional beliefs, which is in accordance with other studies $[5,56]$. Also, older women reported better sexual functioning than younger women. Studies are controversial regarding the impact of age on sexual satisfaction since some studies found a positive effect [23] and others a negative impact [57]. In this case,

\begin{tabular}{|c|c|c|c|c|c|c|c|c|}
\hline \multirow[t]{2}{*}{ Variables } & \multicolumn{4}{|c|}{ Predictors of Sexual Dissatisfaction in Patients } & \multicolumn{4}{|c|}{ Predictors of Sexual Dissatisfaction in Partners } \\
\hline & $\mathbf{R}^{2}\left(\Delta \mathbf{R}^{2} \mathrm{ADJ}\right)$ & $\mathbf{F}$ & B & $\mathbf{T}$ & $\mathbf{R}^{2}\left(\Delta \mathbf{R}^{2} \mathrm{ADJ}\right)$ & F & B & $\mathbf{T}$ \\
\hline Block 1 & $.05(.03)$ & $F(2,106)=2.656$ & & & $.04(.01)$ & $\mathrm{F}(2,72)=1.488$ & & \\
\hline Gender & & & .186 & 1.96 & & & .191 & 1.64 \\
\hline Illness duration & & & -.131 & -1.38 & & & -.040 & -.341 \\
\hline Block 2 & $.38(.35)$ & $\mathrm{F}(5,103)=12 . .63^{\star * *}$ & & & $.22(.16)$ & $\mathrm{F}(5,69)=3.839^{* * *}$ & & \\
\hline Gender & & & .291 & $3.06^{\star *}$ & & & .222 & $2.03^{*}$ \\
\hline Illness duration & & & -.049 & -.609 & & & .038 & .348 \\
\hline Sexual Beliefs and Information & & & -.069 & -.874 & & & .020 & .168 \\
\hline Dyadic Adjustment & & & -.466 & $-5.80^{* * *}$ & & & -.259 & $-2.35^{\star}$ \\
\hline Dysfunctional Beliefs & & & .292 & $2.97^{\star *}$ & & & .351 & $2.98^{\star *}$ \\
\hline
\end{tabular}

Table1: Predictors of Sexual Dissatisfaction in Patients and Partners ${ }^{\star} \mathrm{p}<.05,{ }^{\star *} \mathrm{p}<.01,{ }^{* * *} \mathrm{p}<.001$. 
differences were found on sexual functioning with women reporting better sexual functioning. One may hypothesize that older women may be less demanding regarding their sexuality performance than younger women. This hypothesis needs to be pursued further.

In terms of illness duration, those with diabetes for less than 10 years presented more dysfunctional beliefs than those with a longer illness duration. Patients who have been living with the illness for a longer period of time may have learned more accurate sexual information and, as a result were able to correct their sexual beliefs. This hypothesis also needs to be pursued between in future studies. Another goal of the study was to explore the relationship between the psychological variables, in patients and partners. Results revealed that adherence was positively correlated with sexual information and negatively with dysfunctional beliefs, in patients. This result emphasizes the importance of providing accurate information on sexuality to diabetes patients in order to increase adherence to selfcare behaviors and decrease sexual dysfunctional beliefs $[39,40,42]$. Patients with more information regarding sexuality may be more motivated to follow the diabetic regimen and, therefore, adhere to self-care behaviors since they become aware of the consequences of non-adherence, on their sexual performance. Future studies should address this issue further. However, no partner's variables were correlated with patient's adherence. This result is interesting since partners's dyadic adjustment was found to predict patient's adherence to self-care behaviors in recent diagnosed patients (less than a year) [58]. One may hypothesize that, in this case, since average for diabetes diagnosis was 12 years, partners' dyadic adjustment and sexual beliefs may become a more prominent issue when the couple is struggling with the adaptation to diabetes, right after the diagnosis. Future

Also, sexual satisfaction in patients was positively related to dyadic adjustment, emphasizing the fact that the quality of marital adjustment is associated with more sexual satisfaction, as the literature have shown [19-23]. However, sexual satisfaction was also negatively related to dysfunctional sexual beliefs, indicating that sexual beliefs play an important role in sexual satisfaction [18,29-31]. Therefore, it is important that patients receive correct information about sexuality to change erroneous beliefs, in order to increase sexual satisfaction. These results are in accordance with Adams and collaborators [46], who found beliefs and incorrect sexual information to be related to sexual problems. In fact, problems in sexual functioning may have a negative impact on a couple who is already trying to adapt to a chronic illness such as diabetes.

Patient's sexual satisfaction was also positively related with partner's dyadic adjustment, partner's sexual information, partner's sexual satisfaction and negatively related with partner's dysfunctional beliefs. These relationships were expected since variables related to intimate relationships have been associated with sexual response $[21,28]$.

Finally, female gender, having more sexual dysfunctional beliefs and a reduced dyadic adjustment were predictors of sexual dissatisfaction in patients and partners. Female's patients and partners report more burden associated with diabetes when compared with males [51-53], and this is also true in the case of sexual satisfaction, in this study. Sexual dysfunctional beliefs play an important role in sexual satisfaction [18,29-31], in both patients and partners, which may be related, in this study, to the sample's age. In fact, in this sample, the mean age of patients, was 62 and 50 years for patients and partners, respectively. At this age, it is possible that couples base their beliefs on longitudinal studies should test this hypothesis.

moral criteria, centered on reproduction, and the prevalent sociocultural norms and values, reporting, as a result, more dysfunctional beliefs that may relate to sexual dissatisfaction. A negative dyadic adjustment affects sexual functioning what may explains its predictive role regarding sexual dissatisfaction [21].

The results of the present study emphasize the need for sexual satisfaction and sexuality, in general, to be addressed in medical and nursing routine clinic visits in patients with diabetes. Sexual information and dysfunctional beliefs are particularly relevant for the patient's adherence.

This study shows the importance of including the partner in the "sexuality conversations" when addressing diabetes management, with the patient. Other studies have shown the important role of the partner in the promotion of adherence to medication and selfcare behaviors, in pa-tients with diabetes type $2[17,59,60]$. Finally regarding sexual health, this study highlights the intrinsic relationship between sexual beliefs, dyadic adjustment and adherence, in patients with diabetes type 2 and their partners, emphasizing the need to use a dyadic approach.

\section{Limitations}

Due to the sample size in this study, generalization of results is limited and interpretation should be cautious. The sample was also collected in a very conservative Catholic region regarding sexual beliefs and reported a low level of sexual dysfunctions. Future studies should include bigger samples, include non-Catholic patients and take into consideration marriage duration.

\section{Conclusion}

These results suggest the need for psychological intervention in patients and partners, regarding sexual dysfunctional beliefs and dyadic adjustment taking into consideration their importance for sexual satisfaction. Patients often do not communicate with physicians or partners, as openly and as often as needed, to optimize sexual functioning. Therefore, physicians should include partners when addressing the impact of diabetes on the couple's sexual satisfaction and an open discussion of sexual problems should be a standard procedure in diabetes routine clinic visits.

\section{Competing Interests}

The authors declare that they have no competing interests.

\section{Funding}

This study was found by Bayer Portuguesa (B02/06). The authors wish to thank all patients who agreed to participate in this study.

\section{References}

1. Portuguese Diabetes Society (2015) Diabetes: Factos e Números 2014: Relatório Anual do Observatório Nacional da Diabetes.

2. [No authors listed] (1993) The effect of intensive treatment of diabetes on the development and progression of long-term complications in insulindependent diabetes mellitus. The Diabetes Control and Complications Trial Research Group. N Engl J Med 329: 977-986.

3. de Groot M, Jacobson AM, Samson JA, Welch G (1999) Glycemic control and major depression in patients with type 1 and type 2 diabetes mellitus. $J$ Psychosom Res 46: 425-435. 
Citation: Pereira MG, Marques O, Rodrigues A, Santos J, Pedras S (2016) Sexual Satisfaction in Patients with Diabetes Type 2 and Their Partners. Int J Psychol Behav Anal 2: 117. doi: https://doi.org/10.15344/2455-3867/2016/117

Page 5 of 6

4. Schover LR (2000) Sexual problems in chronic illness. In: Leiblum SR Rosen R C (Ed) Principles and practice of sex therapy, Guilford, New York, pp. 398-422.

5. Wändell PE, Brorsson B (2000) Assessing sexual functioning in patients with chronic disorders by using a generic health-related quality of life questionnaire. Qual Life Res 9: 1081-1092.

6. Coyne JC, Smith DA (1994) Couples coping with a myocardial infarction: a contextual perspective on patient self-efficacy. J Pers Soc Psychol 8 : $43-54$

7. Primomo J, Yates BC, Woods NF (1990) Social support for women during chronic illness: the relationship among sources and types to adjustment. Res Nurs Health 13: 153-161.

8. Trief PM, Himes CL, Orendorff R, Weinstock RS (2001) The marita relationship and psychosocial adaptation and glycemic control of individuals with diabetes. Diabetes Care 24: 1384-1389.

9. Trief PM, Ploutz-Snyder R, Britton KD, Weinstock RS (2004) The relationship between marital quality and adherence to the diabetes care regimen. Ann Behav Med 27: 148-154

10. Trief PM, Wade MJ, Britton KD, Weinstock RS (2002) A prospective analysis of marital relationship factors and quality of life in diabetes. Diabetes Care 25: $1154-1158$

11. Trief P, Sandberg JG, Ploutz-Snyder R, Brittain R, Cibula D, et al. (2011) Promoting couples collaboration in type 2 diabetes: the diabetes support project pilot data. Fam Syst Health 29: 253-261.

12. Cox DJ, Gonder-Frederick L, Saunders JT (1991) Diabetes: Clinical issues and management. In: Sweet J, Rosensky R, Tovian S (Ed) Handbook of clinical psychology in medical settings, Plenum Press, pp. 473-496.

13. Fisher L, Chesla C, Chun KM, Skaff MM, Mullan JT, et al. (2004) Patientappraised couple emotion management and disease management among Chinese American patients with Type 2 Diabetes. J Fam Psychol 18: 302 310.

14. Klausner E, Koenigsberg H, Skolnick N, Chung H, Rosnick P, et al. (1995) Perceived familial criticism and glucose control in insulindependen diabetes mellitus. Int J Ment Health 24: 64-75.

15. Dempster M, McCarthy T, Davies M (2011) Psychological adjustment to Type 2 diabetes and relationship quality. Diabet Med 28: 487-492.

16. Berg CA, Upchurch R (2007) A developmental-contextual model of couples coping with chronic illness across the adult life span. Psychol Bull 133: 920-954.

17. Pereira MG, Pedras S, Machado JC, Ferreira G (2016) Partners' representations of diabetes as mediators between patients' representations and adherence to self-care behaviors, in type 2 diabetes. Psychol Health Med 21: 707-714.

18. Lindau ST, Tang H, Gomero A, Vable A, Huang ES, et al. (2010) Sexuality among middle-aged and older adults with diagnosed and undiagnosed diabetes: a national, population-based study. Diabetes Care 33: 2202 2210 .

19. Lawrance K, Byers ES (1995) Sexual satisfaction in heterosexual long-term relationships: The interpersonal exchange model of sexual satisfaction. Pers Relatsh 2: 267-285.

20. Oggins J, Veroff J, Leber D (1993) Perceptions of marital interaction among black and white newlyweds. J Pers Soc Psychol 65: 494-511.

21. Risen CB (2003) Listening to sexual stories. In: Levine SB, Risen CB Candace B, Althof SE (Ed) Handbook of clinical sexuality for mental health professionals, Brunner-Routledge, New York, pp. 3-19.

22. Schiavi RC, Schreiner-Engel P, Mandeli J, Schanzer H, Cohen E (1990) Healthy aging and male sexual function. Am J Psychiatry 147: 766-771.

23. Young M, Denny G, Young T, Luquis R (2000) Sexual satisfaction among married women age 50 and older. Psychol Rep 86: 1107-1122.
24. Elyasi F, Kashi Z, Tasfieh B3, Bahar A, Khademloo M (2015) Sexual dysfunction in women with type 2 diabetes mellitus. Iran J Med Sci 40: 206-213.

25. Enzlin P, Mathieu C, Demyttenaere K (2003) Diabetes and female sexual functioning: A state of the art. Diabetes Spectr 16: 256-259.

26. Enzlin P, Mathieu C, Van den Bruel A, Bosteels J, Vanderschueren D, et al. (2002) Sexual dysfunction in women with type 1 diabetes: a controlled study. Diabetes Care 25: 672-677.

27. Pedersen MB, Giraldi A, Kristensen E, Lauritzen T, Sandbæk A, et al (2015) Prevalence of sexual desire and satisfaction among patients with screen-detected diabetes and impact of intensive multifactorial treatment: Results from the ADDITION-Denmark study. Scand J Prim Health Care 33: 3-10.

28. Sánchez-Fuentes MM, Santos-Iglesias P, Sierra JC (2014) A systematic review of sexual satisfaction. Int J Clin Health Psychol 14: 67-75.

29. Berg-Cross $L$ (2001) Sexuality and the Couple Relationship. In: Berg-Cross L (Ed) Couples Therapy, The Haworth Clinical Practice Press, New York, pp. 357-362.

30. Kukulo K, Gürsoy E, Sözer GA (2009) Turkish University students' beliefs in Sexual Myths. Sex Disabil 27: 49-59.

31. Owiredu W, Amidu N, Alidu H, Sarpong C, Gyasi-Sarpong CK (2011) Determinants of sexual dysfunction among clinically diagnosed diabetic patients. Reprod Biol Endocrinol 9: 1-11.

32. World Health Organization (1975) Education and treatment in human sexuality: The training of health professionals. Technical Report Series No. 572. Geneva: World Health Organization.

33. Khodabakhshi Koolaee A, Asadi E, Mansoor L, Mosalanejad L, Fathabadi A (2014) A holistic approach to psychological sexual problems in women with diabetic husbands. Iran J Reprod Med 12: 175-182.

34. Thomas A, LoPiccolo J (1994) Sexual functioning in persons with diabetes: Issues in research, treatment and education. Clin Psychol Rev 14: 61-86.

35. Close CF, Ryder RE (1995) Impotence in diabetes mellitus. Diabetes Metab Res Rev 11: 279-285.

36. VevesA, Webster L, Chen TF, Payne S, Boulton AJ (1995)Aetiopathogenesis and management of impotence in diabetic males: four years experience from a combined clinic. Diabet Med 12: 77-82.

37. Webster $L$ (1994) Management of sexual problems in diabetic patients. $\mathrm{Br}$ J Hosp Med 51: 465-468.

38. Vermeire E, Hearnshaw H, Rätsep A, Levasseur G, Petek D, et al. (2007) Obstacles to adherence in living with type-2 diabetes: an international qualitative study using meta-ethnography (EUROBSTACLE). Prim Care Diabetes 1: 25-33.

39. Marinker M, Shaw J (2003) Not to be taken as directed. BMJ 326: 348-349.

40. Horne R (2001) Compliance, adherence and concordance. In: Gard P (Ed) Behavioural approach to pharmacy practice, Blackwell, London, pp. 166183.

41. World Health Organization (2003) Adherence to Long-term Therapy: Evidence for Action

42. Asefzadeh $\mathrm{S}$, Asefzadeh M, Javadi H (2005) Care management: adherence to therapies among patients at Bu-Alicina Clinic, Qazvin, Iran. JRMS 10: 343-348.

43. Spanier GB (1976) Measurement Dyadic Adjustment: new scales for assessing the quality of the marriage and similar dyads. Journal of Marriage and Family 38: 15-28.

44. Pereira MG, Bacalhau R, Sousa P, Machado JC (2015) Research Group: Family Health \& Illness. School of Psychology. University of Minho, Braga. Portugal.

45. Nobre PJ, Pinto-Gouveia J, Gomes FA (2003) Sexual dysfunctional beliefs questionnaire: an instrument to assess sexual dysfunctional beliefs as vulnerability factors to sexual problems. Sex Relation Ther 18: 368-382.

46. Adams SG Jr, Dubbert PM, Chupurdia KM, Jones A Jr, Lofland KR, et al (1996) Assessment of sexual beliefs and information in aging couples with sexual dysfunction. Arch Sex Behav 25: 249-260.

47. Hudson WW (1992) Index of Sexual Satisfaction. Walmyr Assessment Scales scoring Manual. FL, USA: Walmyr Publishing.
Int J Psychol Behav Anal

ISSN: 2455-3867
IJPBA, an open access journal

Volume 2. 2016. 117 
Citation: Pereira MG, Marques O, Rodrigues A, Santos J, Pedras S (2016) Sexual Satisfaction in Patients with Diabetes Type 2 and Their Partners. Int J Psychol Behav Anal 2: 117. doi: https://doi.org/10.15344/2455-3867/2016/117

Page 6 of 6

48. Pechorro P, Diniz A, Vieira R (2009) Satisfação Sexual Feminina: Relação com Funcionamento Sexual e Comportamento Sexuais [Women's Sexual Satisfaction: Relation to Sexual Function and Sexual Behavior]. Análise Psicológica I: 99-108.

49. Almeida JP, Pereira MG (2004) Impacto dos factores psicológicos associados à adesão terapêutica, ao controlo metabólico e à qualidade de vida em adolescentes com diabetes tipo I [The impact of psychological factors associated with adherence, metabolic control and quality of life in adolescents with type 1 diabetes]. Doctoral Thesis. Braga, Portugal: University of Minho.

50. Nobre PJ, Pinto-Gouveia J (2006) Dysfunctional sexual beliefs as vulnerability factors to sexual dysfunction. J Sex Res 43: 68-75.

51. Verbrugge LM (1982) Sex differentials in health. Public Health Rep 97: 417437.

52. Kandrack MA, Grant KR, Segall A (1991) Gender differences in health related behaviour: some unanswered questions. Soc Sci Med 32: 579-590.

53. Peyrot M, Rubin RR (1997) Levels and risks of depression and anxiety symptomatology among diabetic adults. Diabetes Care 20: 585-590.

54. Gimenes HT, Zanetti ML, Haas VJ (2009) Factors related to patient adherence to antidiabetic drug therapy. Rev Lat Am Enfermagem 17: 4651.

55. Yen IH, Moss $\mathrm{N}$ (1999) Unbundling education: A critical discussion of what education confers and how it lowers risk for disease and death. Ann N Y Acad Sci 896: 350-351.

56. Bacon CG, Mittleman MA, Kawachi I, Giovannucci E, Glasser DB, et al. (2003) Sexual function in men older than 50 years of age: results from the health professionals follow-up study. Ann Intern Med 139: 161-168.

57. De Ryck I, Van Laeken D, Nöstlinger C, Platteau T, Colebunders R Eurosupport Study Group (2012) Sexual satisfaction among men living with HIV in Europe. AIDS Behav 16: 225-230.

58. Pereira MG, Costa V, Oliveira D, Ferreira G, Pedras S, et al. (2015) Patients and Spouses' Contribution Toward Adherence to Self-Care Behaviors in Type 2 Diabetes. Res Theory Nurs Pract 29: 276-296.

59. Pereira MG, Pedras S, Machado JC (2014) Family variables as moderators between beliefs towards medicines and adherence to self-care behaviors and medication in type 2 diabetes. Fam Syst Health 32: 198-206.

60. Pereira MG, Machado JC, Sousa MR, Pedras S (2014) A study of a couple with type 2 diabetes: dyadic adjustment and psychological morbidity. Rev Assoc Med Bras (1992) 60: 318-326. 